\title{
A Family of Active Iridium Catalysts for Transfer
}

\section{Hydrogenation of Ketones}

Zaheer E. Clarke, ${ }^{a}$ Paul T. Maragh, ${ }^{a}$ Tara P. Dasgupta, ${ }^{a}$ Dmitry G. Gusev, ${ }^{b}$ Alan J. Lough ${ }^{c}$ and Kamaluddin Abdur-Rashid $*^{d}$

${ }^{\text {a }}$ Department of Chemistry, University of the West Indies, Mona, Kingston 7, Jamaica, W.I.

${ }^{\mathrm{b}}$ Department of Chemistry, Wilfrid Laurier University, Waterloo, Ontario N2L 3V5 Canada.

${ }^{c}$ Department of Chemistry, University of Toronto, Toronto M5S 3H6 Canada

${ }^{\mathrm{d}}$ Kanata Chemical Technologies Inc., 310-101 College Street, MaRS Centre, South Tower, Toronto, ON M5G 1L7 Canada. www.kctchem.com

kamal@kctchem.com

ABSTRACT

The air-stable iridium pincer dihydridochloro complex $\operatorname{IrH}_{2} \mathrm{Cl}\left[\left({ }^{\mathrm{i}} \mathrm{Pr}_{2} \mathrm{PC}_{2} \mathrm{H}_{4}\right)_{2} \mathrm{NH}\right]$, 1, was prepared by warming a stoichiometric mixture of $\left[\operatorname{IrCl}(\mathrm{coe})_{2}\right]_{2}$ and $\left({ }^{\mathrm{i}} \mathrm{Pr}_{2} \mathrm{PC}_{2} \mathrm{H}_{4}\right)_{2} \mathrm{NH}$ at $80^{\circ} \mathrm{C}$ in 2-propanol. Reaction of $\mathbf{1}$ with $\mathrm{KO}^{\mathrm{t}} \mathrm{Bu}$ in an aprotic solvent resulted in the clean formation of the amidodihydride complex $\left.\operatorname{IrH}_{2}\left[{ }^{\mathrm{i}} \mathrm{Pr}_{2} \mathrm{PC}_{2} \mathrm{H}_{4}\right)_{2} \mathrm{~N}\right], 2$. Treatment of $\mathbf{1} / \mathrm{KO}^{\mathrm{t}} \mathrm{Bu}$ or $\mathbf{2}$ with 2-propanol resulted in the formation of the moderately air-stable iridium pincer trihydride complex $\operatorname{IrH}_{3}\left[\left({ }^{\mathrm{i}} \mathrm{Pr}_{2} \mathrm{PC}_{2} \mathrm{H}_{4}\right)_{2} \mathrm{NH}\right], 3$. The trihydride and amidodihydride compounds in the absence of a base are exceptionally active catalysts for the transfer hydrogenation of ketones in 2-propanol, whereas $\mathbf{1}$ is totally inactive as a catalyst under comparatively 
similar reaction conditions. On the other hand, a mixture of $\mathbf{1}$ and $\mathrm{KO}^{t} \mathrm{Bu}$ in 2-propanol is very effective for the catalytic transfer hydrogenation of ketones under comparable reactions conditions as $\mathbf{2}$ or $\mathbf{3}$.

A bifunctional ionic transfer hydrogenation mechanism is proposed for the catalytic process, involving the transfer of hydrogen from the mutually cis $\mathrm{N}-\mathrm{H}$ and $\mathrm{Ir}-\mathrm{H}$ moieties to the substrate to give the alcohol product and the unsaturated 16-electron amidodihydride intermediate. This is followed by rapid regeneration of the trihydride catalyst by abstraction of hydrogen from 2-propanol, with the concomitant formation of acetone. 